\title{
1 Semi-automated roadside image data collection
}

2 Neal Pilger ${ }^{1}$, Aaron Berg ${ }^{1}$, Pamela Joosse ${ }^{2}$

3 'Department of Geography, University of Guelph, Guelph, ON, N1G 2W1, Canada

$4{ }^{2}$ Agriculture and Agri-Food Canada, 174 Stone Road W., Guelph, ON NIG 4S9, Canada

5 Correspondence to: Neal Pilger (npilger@uoguelph.ca)

\section{Abstract.}

8 This article describes the development of a mobile roadside survey procedure for obtaining corroboration

9 data for the remote sensing of agricultural land use practices. The key objective was to produce a dataset of 10 geo-referenced roadside digital images that can be used to compare to in-field photos for measuring 11 agricultural land use and land cover associated with crop residue and cover cropping in the non-growing 12 season. It was concluded that a very high level of correspondence ( $>90 \%$ level of agreement) could be 13 attained using a mobile survey vehicle, as presented in this research, to detailed in-field ground verification 14 data. Classification correspondence was carried out against 114 field sites with a level of agreement at $1593 \%$. The few discrepancies were in the differentiation of residue levels between $30-60 \%$ and $>60 \%$, both 16 of which may be considered as achieving conservation practice standards. The mobile roadside image 17 capture has advantages of relatively low cost and insensitivity to cloudy days, which often limits optical 18 remote sensing acquisitions during the study period of interest. We anticipate that this approach can be used 19 to reduce associated field costs for ground surveys, while expanding coverage areas and may be of interest 20 to industry, academic and government organizations for more routine surveys of agricultural soil cover 21 during periods of seasonal cloud cover.

\section{Introduction}

23 The identification and verification of in-field characteristics is an inherent component of the remote sensing 24 of land use and land cover (LULC), and change detection classifications for the assessment of post-harvest 25 tillage and cover crop practices (Hussain, et al., 2013). Traditionally, the generation of training and 26 evaluation data sets for remote sensing classification approaches rely on in-field physical measures that 27 include both nadir and oblique image capture, physical counts of residue to bare earth percentages over a 28 series of 3 - 5 geo-referenced sample plots to represent a satellite pixel (e.g. Pacheco and McNairn, 2010; 29 AAFC, 2011; Laamrani et al. 2017). Such methods, while effective in the categorization of crop residue 30 classes for research purposes, are costly, labour intensive, and limited logistically to characterize a large 
1 region, such as at the county level, in quantifying annual tillage and cover crop use and trends. These

2 methods are also inefficient for situations when generalized classes of landcover are sufficient for program 3 and policy decision making activities.

5 The common post-harvest activities used in agriculture land management in the southern Ontario study region include conventional (CV), conservation (CS) and no tillage (NT), and potentially cover cropping practices; defined as follows. Conventional tillage is a common post-harvest practice for many large-scale agricultural operations. This tillage practice involves incorporating, or turning residual plant matter into the soil following harvest, and with additional seedbed preparation prior to the following planting cycle.

10 Conventional tillage is effective at controlling weeds, however, the burial of residue, and the increased 11 disaggregation of the soil encourages runoff and erosion (Moreira et al., 2016; Dam et al., 2005). This 12 practice also leads to an increase in carbon release to the atmosphere via accelerated organic soil matter 13 breakdown, which has been linked to climate change (Silva-Olaya et al., 2013). Aside from these issues is 14 the cost in time and fuel (if using mechanized tools - e.g. tractors) of repeated passes over the field. 15 Conservation tillage (CS) and No-tillage (NT) use implements designed to limit soil disturbance to reduce 16 surface disruption, and leave a protective organic layer (crop residue) between harvest and subsequent 17 plantings (Steiner, 2002). The difference between CS and NT residue classes lie in the amount of material 18 left between harvest and replanting on the surface, where CS residue is typically classified with residue 19 coverage between 30 and 60 percent, and NT categorization having in excess to 60 percent, as opposed to 20 residue cover significantly less than 30 percent for conventional (CV) practices. Both CS and NT practices 21 have been shown to influence soil microbial biomass (Mathew, et al., 2012; Govaerts et al., 2007; 22 Spedding et al., 2004) and hydraulic properties (Blanco-Canqui et al., 2017; Gozubuyuk el al., 2014) by 23 improving soil quality via an increase in soil organic matter (Daughtry and Hunt, 2008). Both methods 24 reduce soil disturbance, compared to conventional methods, and therefore assist in carbon sequestration 25 (Dolan et al., 2006; Halvorson et al., 2002; Angers et al., 1997). Maintaining large amounts of non26 photosynthetic plant material on the surface, no-till practices somewhat mimic a natural ecosystem scenario 27 (Jabro et al., 2016; Arshad et al., 1999).The added layer of plant material, however, can trap moisture and create a fertile environment for both fungal and weed development (Govaerts et al, 2007).

30 Another practice employed after crop harvest is to establish a living plant green cover. In this study, green 31 cover in fields included fields planted to perennial crops (i.e. predominantly alfalfa or alfalfa/grass 32 mixtures), winter cereals (i.e. winter wheat predominantly) as well as cover crops (e.g. Oats, oilseed radish, 33 clover). The green cover secures the inverted soil against wind erosion and maintain moisture levels and 
1 material for decomposition prior to spring planting. Green cover species with deep tap roots can be important to breaking through compacted layers and may be considered a fourth tillage practice (Derpsch,

3 2003). If green cover can get established early enough that there is significant cover of the soil, it can

4 effectively dissipate direct rainfall striking the soil surface promoting diffuse infiltration and limiting 5 potential for surface runoff and erosion.

As of 2009, Agriculture and Agri-Food Canada (AAFC) implemented a crop inventory database in Canada 8 using satellite remote sensing data and ground-based verification (Fisettte et al., 2014). While orbital, or 9 high altitude aerial remote sensing is routinely employed for land-use classification, optical remote sensing 10 methods are limited by opaque atmospheres (Thoma, et al., 2004) as regularly present in both the spring 11 pre-planting; and in fall, post-harvest. While Radar remote sensing has been utilized to circumnavigate 12 such issues, there are remaining issues in the collection of ground data to develop wider-scale 13 implementation of remote sensing classification approaches for non-growing season land management 14 practices. Planning field verification missions, being costly from a personnel and travel perspective, can be 15 minimized using single vehicle large scale surveys, which function equally well in clear or overcast 16 conditions. Roadside surveys, however, primarily focus on oblique horizontal/ landscape data capture, as opposed to vertical nadir views afforded by most high altitude airborne and orbital platforms.

19 An issue prevalent in using oblique photography for landscape evaluation lies in the variable scale inherent 20 in such images as function of image tilt, focal length, sensor resolution, and camera height (Remondino and 21 Gerke, 2015). Subsequently, the background image pixels are representative of a larger geographic area 22 than their foreground counterparts, and effective quantification of surface variation is limited to relative, 23 rather than absolute measures (Stockdale, et al., 2015). For generally homogeneous landscape 24 categorization, however, especially if being used for the generation of ground-truth training sites against nadir-view high altitude aircraft or satellite remote sensing classification, such methods are suitable for rapid ground class assessment. The virtue in oblique imagery lies in its simplicity of interpretation and understanding, being the way in which we are accustomed to viewing the world (Remondino and Gerke, 28 2015).

30 The objective of this study was to establish a baseline percentage of Ontario county level agriculture fields 31 employing different tillage practices through the development, and testing of a ground survey data, vehicle32 mounted, camera system. The survey system was developed to compare to in-field photos for measuring 33 soil cover in order to determine the value of roadside acquisition for both routine ground truth data 
1 collection for remote sensing analysis of soil cover, and the utility of using such data collection as a

2 surrogate to standard practices which are reliant on orbital remote sensing classification.

\section{Methodology}

\section{Site Location}

6 Fieldwork was conducted in Elgin and Essex county in South-western Ontario, Canada (Figure 1).

7 Dominant crops in these areas include corn (Zea mays), and soybean (Glycine max), and winter wheat

8 (Triticum aestivum L.) grown in rotation, interspersed occasionally with perennial forages. As discussed

9 above, various practices are followed after harvest including use of cover crops, conventional, CT and NT,

10 resulting in different soil surface cover conditions during the non-growing season.

11

12

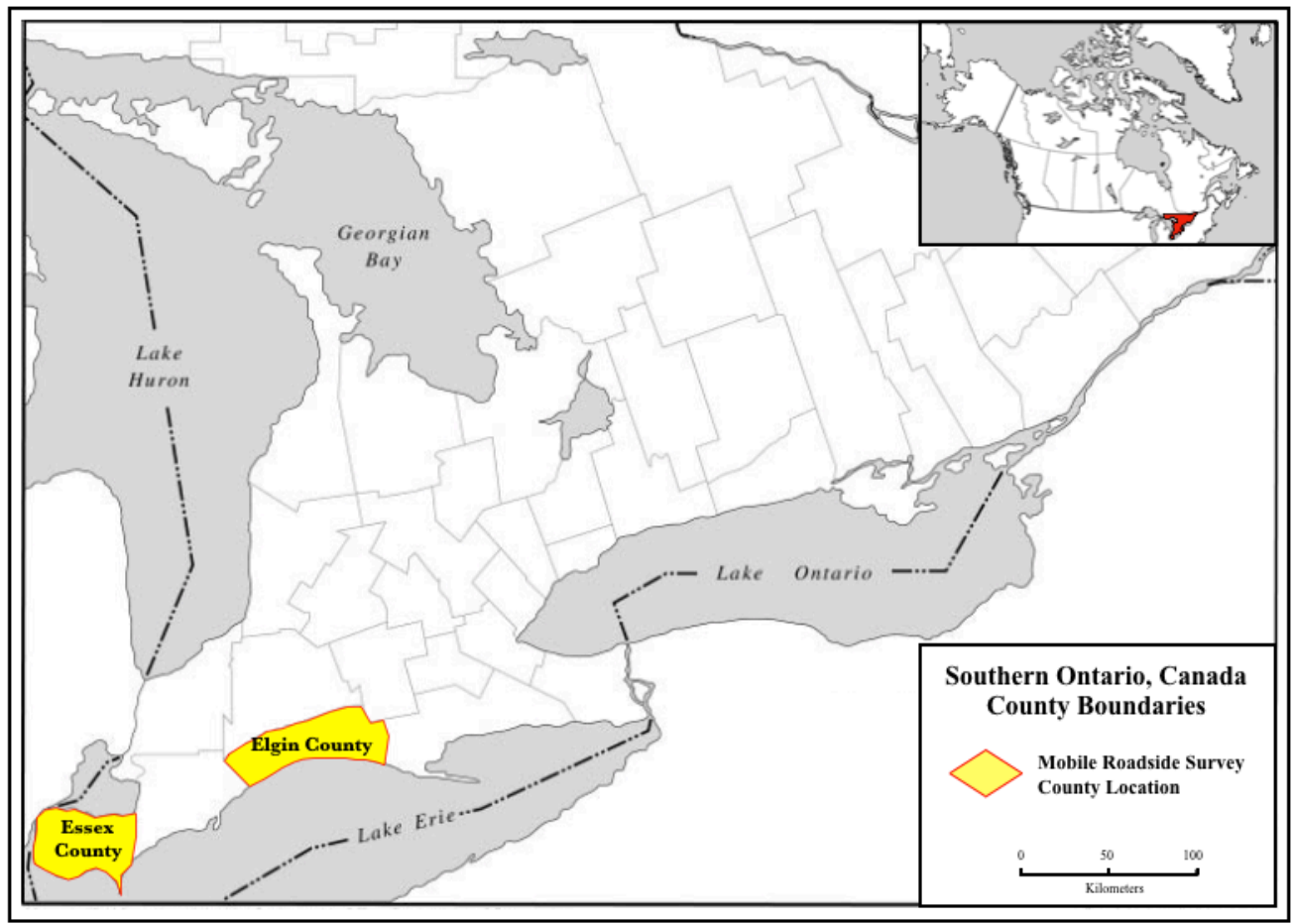

Figure 1. Map of roadside survey area locations. 


\section{Instrumentation}

3 The vehicle mounted road side imagery system (Figure 2) included a pair of Garmin VIRB XE cameras

4 and a full-spectrum (near-infrared) modified GoPro HERO camera. The imaging systems were mounted

5 perpendicular to the vehicles travel direction, extended above permanent mounting brackets to an elevation

6 of $2.3 \mathrm{~m}\left(7.5^{\prime}\right)$ on the right (curb-side) and up to $2.6 \mathrm{~m}\left(8.5^{\prime}\right)$ on the left (driver-side) above ground level to

7 compensate for the additional distance to drivers-side fields. The extension poles were further reinforced

8 against vibration using foam insulated cable ties to roof rails, and support mounts on the vehicle. A large

9 proportion of the driving route for each county was comprised of rough gravel, or packed dirt roads; hence

10 a 4WD with a modified soft suspension was required to reduce vibration on the imaging platforms

11 themselves. Further the 4WD vehicle with its higher ground clearance allowed for higher mounting of the

12 side-looking cameras.

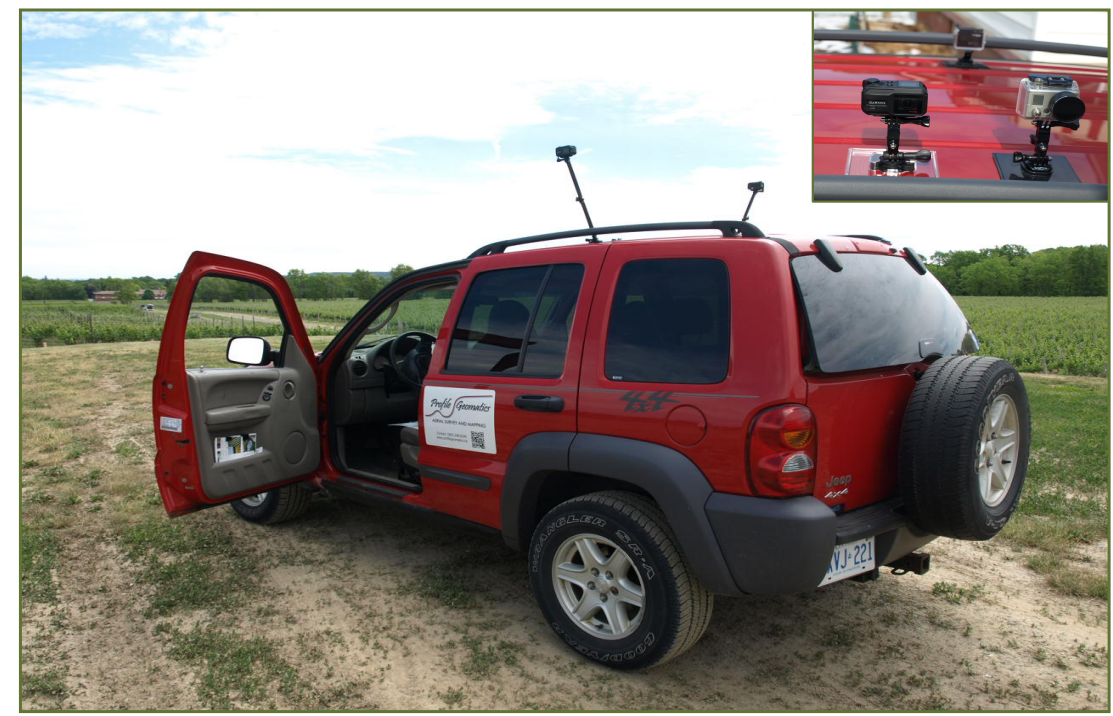

Figure 2. Roadside survey vehicle camera system with roof-top camera mounts

Data collection for Essex and Elgin County were carried out on May 18, and 20, 2016, respectively under clear sky conditions. Acquisition plans were conducted to coincide with Landsat 8 OLI overpass and the concurrent in-field ground-truth data collection for each respective area. Data collection was carried out in

21 this manner to produce a value-added product that could be employed for ground-truth evaluation of future 22 studies employing the Landsat orbital platform. Thus, permitting additional use for the collected imagery in 
a secondary land-use study not covered in this pilot experiment.

\section{Driving Parameters}

Route maps were designed for the two sampling locations to minimize overlap in image acquisition, and to ensure adequate coverage of AAFC field plots for comparison between mobile collected, and in-field static image capture and residue quantification (Appendix A). Driving speed was maintained between 40-45

$11 \mathrm{~km} / \mathrm{h}$ to ensure image capture of every field with shutter actuation on each camera set at 5-second intervals.

12 Following a previous field survey in Elgin County on 2016-05-11, it was determined that a reduced driving 13 speed be implemented to reduce vibration through the vehicle to the elevated camera platforms. Therefore, 14 a speed restriction of 40-45 km/hr. was used on the subsequent (Essex and Elgin County - 2016.05.18, $15 \quad 2016.05 .20$, respectively) acquisitions.

17 Driving speed and shutter actuation are inherently related, and based on average roadside field dimensions. 18 The following equation was used to calibrate both shutter actuation and driving speed.

$$
\mathrm{SA}=\mathrm{DS}(\mathrm{m} / \mathrm{sec}) /(\mathrm{MFW}(\mathrm{m}) / 3)
$$

(Equation 1)

22 Where SA = shutter actuation interval in seconds; DS = vehicle driving speed in metres per second; MFW 23 = mean field width in metres, based on pre-site planning of field polygon network for each respective 24 sample area. This value is then divided by 3 to ensure a minimum of 2 usable images for each respective 25 field. Multiple field image captures are required in event that undesired features (people, vehicles, trees, 26 etc.) are visible at the forefront of the imaging plane. 


\section{Data Processing}

\section{Data Transfer and Sorting}

4 Following each site acquisition, image files were transferred to a desktop computer for sorting. A total of

5 18,462 images were acquired for the 2 routes. The images were manually sorted by site, date, and look

6 direction for the particular camera whereby any images not meeting the requirements of the project were

7 subsequently deleted. Examples of deleted scenes include images of forests, houses, quarries, intersections,

8 overpasses, non-agricultural structures, road-vehicles, or any that contained identifiable footage of

9 individuals.

\section{Geometric Rectification}

11 An issue prevalent with wide-angle oblique image capture is the so-called fish-eye, or barrel effect. The 12 geometric distortion in the radial direction, while present in all aspects away from the centroid of the 13 imaging plane, results from compression in peripheral regions allowing for a wide-angle view to be 14 presented in the image plane (Kim and Pail, 2015). Such distortion presents issues in many land-use studies 15 by virtue of a variable pixel-to-ground scale across the image plane, and the removal of lens distortion is 16 often preferred in multi-class image classification, especially where volumetric measures of scene features 17 are required (Chow, et al., 2018; Stockdale, et al., 2015). While not absolutely pertinent to this land-use 18 study, image correction was performed using Liquivid(C) Video Fisheye Removal software; other open19 source image correction software, such as Mathmap:GIMP; GML Undistorter; RadCor; Photivio; 20 FisheyeGL, among others (listoffreeware.com, 2019) are also readily available for the correction of wide 21 angle lens distortion. The correction permits cross platform image sharing for a subsequent study where 22 geometrically rectified imagery is required.

\section{Coordinate Encoding and Verification}

24 The GPS vehicle mounted cameras include horizontal geographic lat/long coordinate information in 25 addition to other variables including, elevation, slope and aspect that are transferrable to the imagery via 26 still-to-video image conversion. Transfer of ancillary information to coordinate geometry was performed by 27 creating a stop-motion video comprised of the 4 sorted, and geometrically rectified image data-sets (left 28 and right for 2 acquisitions), then deconstructing the video back to individual static images. The process 29 allowed for extraction of coordinate coding for each image and the generation of a point for each image 30 location to be displayed in a GIS environment. In this instance we used ESRI ArcGIS, however the same 
1 methodology may equally be employed using many open source alternatives (e.g. GRASS, WhiteBox,

2 QGIS, uDIG, etc).

3

\section{GIS Integration and Map Overlay}

\section{Geodatabase creation}

6 A geodatabase of the imagery was created within an ESRI ArcGIS 10.1 environment. The roadside images

7 were linked to a point feature class layer for spatial identification based on the inherent coordinate data

8 captured coincident with the roadside imagery (Figure 3). Determining the point feature classes were then

9 linked to individual field polygons to allow for photo identification of each field within the study region.

10 This procedure allows the user to zoom in to each field location and visually assess any roadside images

11 connected to the given field polygon (Figure 4).

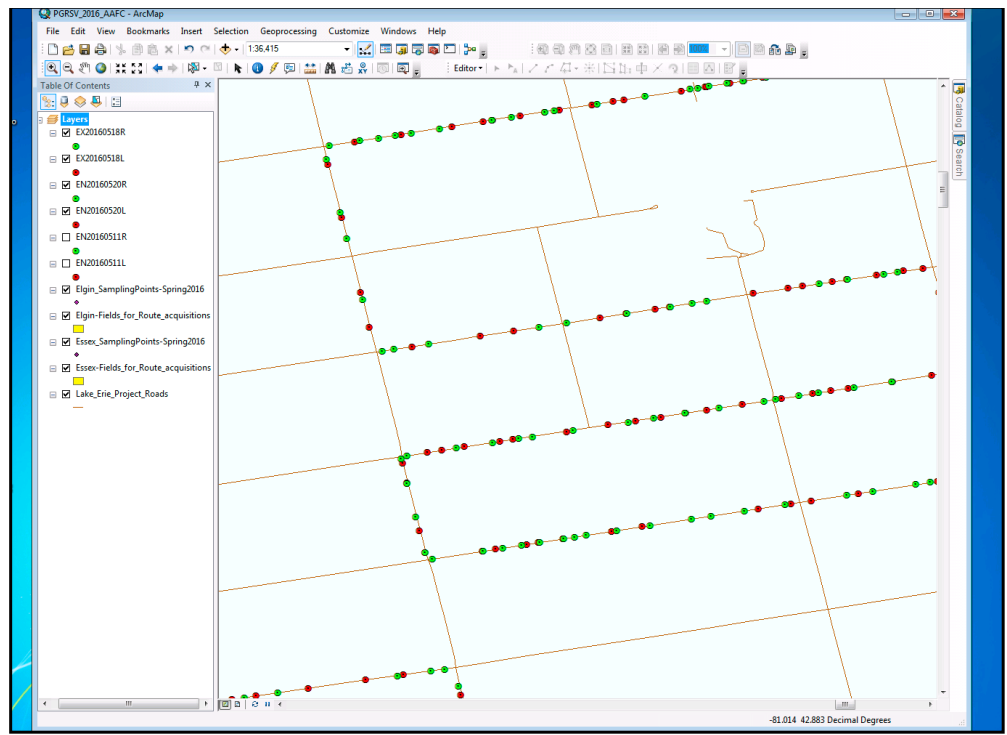

14 Figure 3. Geo-referenced roadside survey image locations. Green $=$ right viewing, Red $=$ left viewing to vehicle geo-referenced points. 


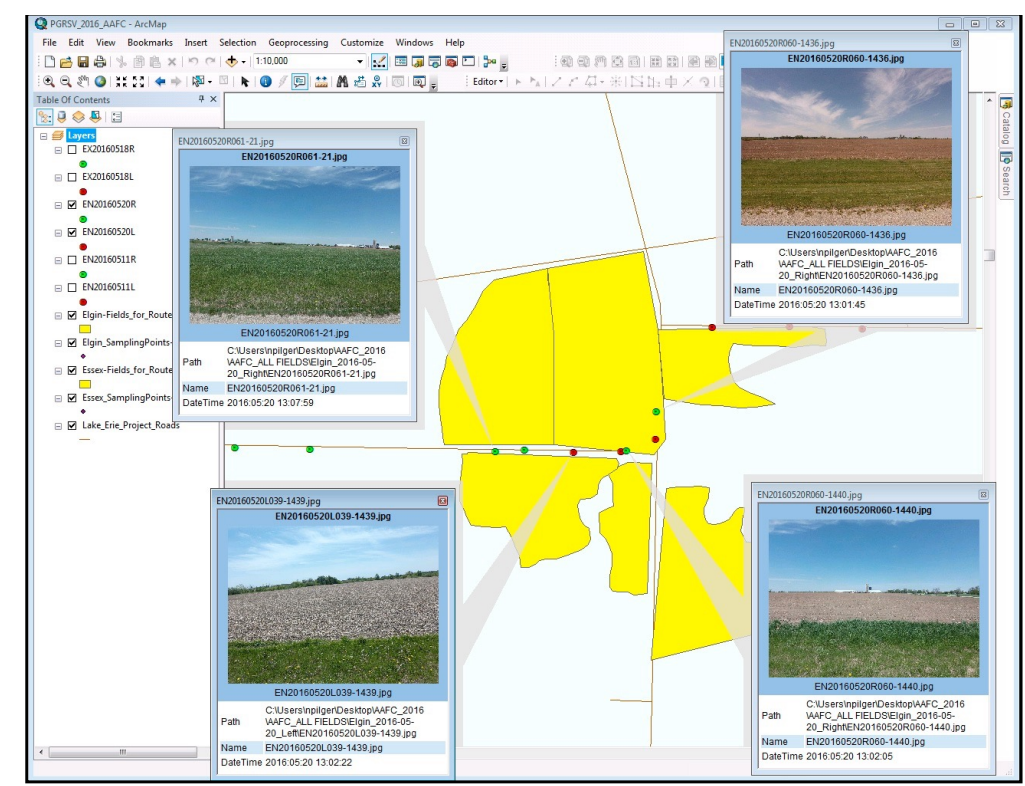

Figure 4. Hyperlinked image files to point and field polygon network.

4 A benefit of this procedure is the ease of updating visual examples of each respective field in a given area,

5 and the immediate comparison to changes in both crop type and tillage practices. The technique is

6 adaptable to be carried out over a series of years, while minimizing the time and costs to be physically

7 present in the reference, or validation fields themselves. Images captured by field research were assessed by

8 OMAFRA staff trained in conducting visual surveys to belong to one of 5 to 6 residue classes, which were

9 then rescaled into the 4 cover classes (Figure 5) to be used in validating the oblique mobile image capture.

10
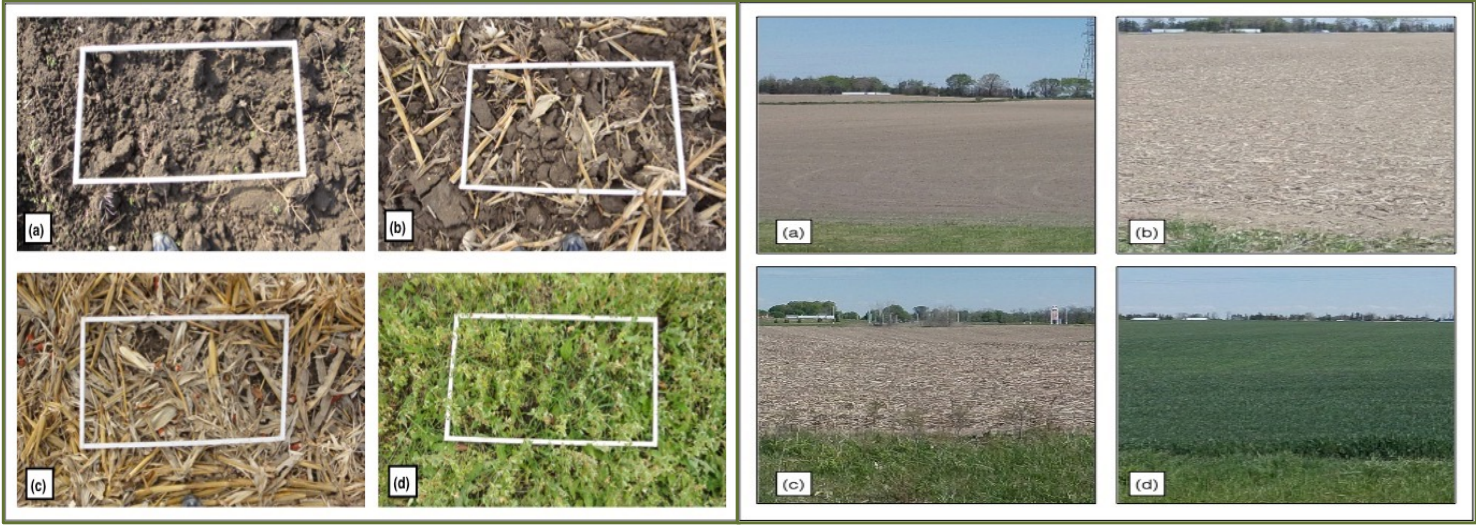

Figure 5. Classes as recorded using in-field, and roadside survey. (a) Conventional; (b) Conservation; (c) NoTill; and (d) Green Cover. 
1 Ground-based validation of roadside image capture was performed using data from 114 research sites across the two counties collected by AAFC scientists coincident with roadside image capture. The in-field research sites were evaluated for residue percentage using a photo-grid sampling technique where average counts were derived from random selections on three digital images captured at 90 degrees from surface normal, or nadir view over 0.75 x 1.0 meter survey quadrats. Residue and green cover counts of the photos were performed using of $10 \times 10$ digital grids, representing 100 points for each imaging frame (Laamrani,

et al., 2017, 2018), where cover percentage was based on presence or absence over each of the 100 grid 8 intersection points and categorized as conventional (0\% - 30\%); Conservation (30\% - 60\%); and No-Till $9(60 \%-100 \%)$ residue (figure 6). The green cover class was assigned when $>90 \%$ field was visually 10 composed of green, actively photosynthesizing vegetation.

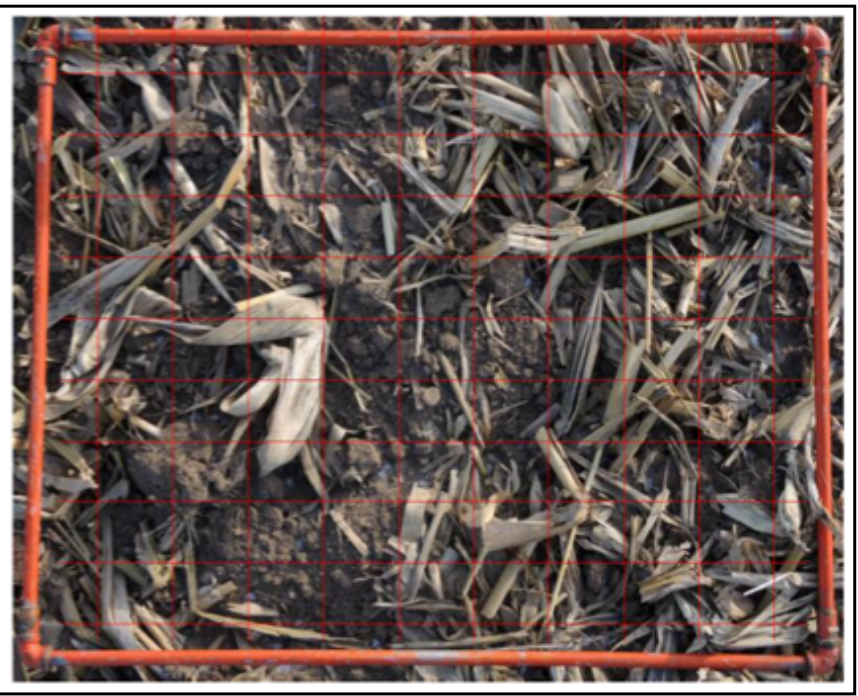

Figure 6. Superimposed 10 x10 photo grid over corn residue field sample quadrant.

\section{Results}

34 A confusion matrix (Table 2) was used to compare the mobile roadside imagery classes against in-field collected data classes (Figure 5) for the 114 research sites distributed over the two counties surveyed during

36 this research project. While overall agreement between roadside collected imagery (RS) and in-field (IF) 
measures was strong, there are some minor areas of confusion, primarily between conservation (CS) and

no-till (NT) fields. This may be explained by the visual similarity at distance from the roadside between these two land-classes (Figure $5 \mathrm{~b}$ and c (right side)).

Table 2. Error matrix mobile roadside (RS) oblique vs ground collected nadir in-field (IF) imagery, for conventional tillage (CV); conservation tillage (CS); no-till (NT); and green cover (GC) practices. Validation carried out against 114 AAFC field sites in Elgin and Essex County. Omission and Commission error values for each land class are reported in the last row and column respectively, with an overall accuracy of $93 \%$.

\section{Challenges and Environment} acceptable in this case.

\begin{tabular}{|c|c|c|c|c|c|c|}
\hline $\boldsymbol{n}=\mathbf{1 1 4}$ & IF-CV & IF-CS & IF-NT & IF-GC & Total & Error \\
\hline RS-CV & 30 & 1 & 0 & 0 & 31 & $3.2 \%$ \\
\hline RS-CS & 0 & 21 & 5 & 0 & 26 & $19.2 \%$ \\
\hline RS-NT & 0 & 2 & 37 & 0 & 39 & $5.1 \%$ \\
\hline RS-GC & 0 & 0 & 0 & 18 & 18 & $0 \%$ \\
\hline Total & 30 & 24 & 42 & 18 & & \\
\hline Error & $0 \%$ & $12.5 \%$ & $11.9 \%$ & $0 \%$ & & $\mathbf{O A}=\mathbf{9 3 \%}$ \\
\hline
\end{tabular}

Another issue relating to confusion between the tillage classes involves the look direction variation between nadir and oblique image capture. For example, a harvested field of corn will appear to contain higher levels of residue in an oblique image, as we are viewing the residue from the side, and overlap occurs as a function of perspective, whereas in a nadir view a greater proportion of bare soil will be visible within the image. As both Conservation and No-Till meet thresholds representative of conservation methods (i.e. $>30 \%$ cover for soil erosion protection), the misclassification between the two is deemed

While few, there are a number of challenges that must be addressed in carrying out an operation of this scope. These will be addressed in order of technological importance. Weather, is paramount if requiring coincident optical satellite imagery with field interpretations; besides this requirement, for roadside data collection the following are the key challenges to overcome. 
2 Driving speed: technically higher speeds should lead to a blurring effect on short distance image capture.

3 This is especially true when light levels are low. However, in comparative tests following all acquisitions,

4 shots captures at $40 \mathrm{~km} / \mathrm{hr}$ in bright clear atmospheric conditions were only marginally sharper than those

5 captured at $60 \mathrm{~km} / \mathrm{hr}+$ during overcast conditions. The real benefit of a reduced driving speed, therefore,

6 lies in a reduction of vibration from wheel-base through to camera mount.

8 Wind speed: as with vehicular velocity above, higher wind speeds increase vibration through the vehicle

9 and the extended camera mounts. Vibration can significantly affect image clarity and subsequent

10 assessments. From this pilot project there is evidence in image capture footage where heavy gusts can also

11 offset the horizontal plane of the camera. While efforts were in place to minimize such effects (insulated,

12 damping core wire ties from cameras and extension poles to vehicle roof-rails) excessive gusting can affect

13 the horizontal image plane.

15 Shutter actuation: Shutter actuation, is intrinsically linked to driving speed, and external light conditions.

16 While one could capture images at up to $10 \mathrm{shots} / \mathrm{sec}$. the associated image sorting time required if 17 conducted manually as in this project would render such operation financially unsound. Setting camera 18 aperture to ensure that every field is captured a minimum of 3 times in a pass required pre-assessment of 19 field orientation, and dimensions as this will vary by the land survey system by geography. This enabled 20 calculation of maximum driving speed (in this case it varied between 30-50 km/hr) with a 3-5 second 21 actuation interval.

23 Privacy concerns: Though listed last, privacy concerns are paramount in post production though not a 24 technical issue. Any images where people, especially children; vehicles; homes; etc. are visible and 25 identifiable have potential to raise privacy concerns and cannot legally be distributed through any 26 commercial or government shared channels. With a sound editing and sorting methodology, any such images would be deleted in an expedient manner, following a best practice protocol.

\section{Conclusions}

30 Key benefits of the mobile ground-based reference data collection method described in this paper are the 31 flexibility garnered through not requiring any specific meteorological conditions, as is the case with most 32 optical airborne, and orbital platforms; enhanced safety by removing manual real-time roadside 33 classification, and driver distraction by incorporating an automatic imaging system.; and creating archival 
1 footage on land and lands conditions for future reference. Temporally, collection dates are limited in tillage 2 assessment studies carried out in temperate climates. Ground-truth imagery is required with in the late 3 autumn, prior to snowfall; or in late spring, following snowmelt, but prior to any seedbed preparation 4 practices carried out prior to planting. In southwestern Ontario, skies are generally overcast for the majority 5 of days in these narrow temporal windows, thus limiting traditional classification using orbital, or high 6 altitude airborne image capture. Specific fields that have not been harvested at the time of roadside image 7 capture, may readily be re-visited, or such field-data may be in-filled at a later date, either via direct contact 8 with land holders, or through other citizen provided reference data (Foody, 2015). Mounted with opposing 9 side viewing cameras, the roadside survey vehicle was shown to be highly efficient in the collection of geo10 referenced imagery of up to 500 fields per hour, with an overall level of agreement to in-field ground 11 surveys at 93 percent, employing a single vehicle, and 1-2 operators, producing a more reliable and robust 12 data-set for extrapolation to larger areas, compared to the 5 to 10 fields which could be surveyed in the 13 same time frame using conventional in-field methods.

14 Another benefit is that time series of these surveys would permit change detection analysis over subsequent 15 years to evaluate climate adaptations, routine monitoring for productivity, soil surveys and yield estimates 16 (Fisette, et al., 2014, Kennedy, et al., 2009); to determine impacts of regulations that may result in the 17 adoption of particular cropping practices in the province (Vercammen, 2011); and to inform recommended 18 methodologies that can be used by industry, provincial or federal organizations for more routine 19 measurement of soil cover.

21 This project demonstrated that this method can provide rapid determination and dissemination of post22 harvest tillage and green cover practices over county level areas even where atmospheric conditions are unfavourable for satellite remote sensing, while improving on financial, temporal, and safety costs for in24 field verification data acquisition.

26 While this study focused on the resource-based utility of employing mobile roadside image capture for use 27 in characterizing post-harvest field conditions, a follow-up project is underway to investigate residue 28 decomposition rates and subsequent field operations to determine optimal timing in such mobile field 29 surveys. Also, based on date of image capture, some fields showed evidence of recent soil turning, 30 therefore the fields analyzed may indicate higher levels of soil disturbance being classed as conventional 31 tillage than what may in fact be a conservation practice carried out by the landowner. In this respect, one 32 must take into account the temporal influence of any tillage residue survey. With many agricultural surveys 
1 being carried out coincident with satellite overpass, potential classification errors, as described in this manuscript, stress the benefit of a non-orbital dependent classification technique.

\section{Acknowledgements}

This research was supported by funding from the Ontario Ministry of Agriculture, Food and Rural Affairs and Agriculture and Agrifood Canada. Thanks to Ahmed Laamrani, for compiling driving route maps; AAFC field scientists for ground verification data; and to Profile Geomatics, Canada, for providing the use of their roadside survey vehicle and imaging equipment. Additional software and hardware support was provided by the Department of Geography, University of Guelph, Canada.

\section{References}

AAFC.: Methodology for Residue Cover Mapping, v.1.0. Earth Observation Research Branch Team. Internal Document, Agriculture and Agri-Food Canada, 2011.

Angers, D.A., Bolinder, M.A., Carter, M.R., Gregorich, E.G., Drury, C.F., Liang, B.C., Voroney, R.P., Simard, R.R., Donald, R.G., Beyaert, R.P., Martel, J.: Impact of tillage practices on organic carbon and nitrogen storage in cool, humid soils of eastern Canada. Soil Tillage Res. 41, 191-201, https://doi.org/10.1016/S0167-1987(96)01100-2, 1997.

Arshad, M.A., Franzluebbers, A.J., Azooz, R.H.: Components of surface soil structure under conventional and no-tillage in northwestern Canada. Soil Tillage Res. 53, 41-47, https://doi.org/10.1016/S01671987(99)00075-6, 1999.

Blanco-Canqui, H., Wienhold, B.J., Jin, V.L., Schwer, M.R., Kibet, L.: Long-term tillage impact on soil hydraulic properties. Soil \& Tillage Res. 170, 38-42, https://dx.doi.org/10.1016/j.still.2017.03.001, 2017.

Chow, J.C.K., Detchev, I., Ang, K.D., Morin, K., Mahadevan, K., Louie, N.: Robot Vision - Calibration of wide-angle lens cameras using collinearity Condition and K-Nearest Neighbour Regression. Ecological Econ. 111, 93-99, https://doi.org/10.5194/isprs-archives-XLII-1-93-2018, 2018.

Dam, R.F., Mehdi, B.B., Burgess, M.S.E., Madramootoo, C.A., Mehuys, G.R., Callum, I.R.: Soil bulk density and crop yield under eleven consecutive years of corn with different tillage and residue practices in a sandy loam soil in Central Canada. Soil Tillage Res. 84, 41-53, https://doi.org/10.1016/j.still.2004.08.006, 2005.

Dolan, M.S., Clapp, C.E., Allmaras, R.R., Baker, J.M., Molina, J.A.E.: Soil organic carbon and nitrogen in a Minnesota soil as related to tillage, residue and nitrogen management. Soil Tillage Res. 89, 221-231, https://doi.org/10.1016/j.still.2005.07.015, 2006.

Daughtry, C.S.T., Hunt, E.R. Jr.: Mitigating the effects of soil and residue water contents on remotely sensed estimates of crop residue cover. Remote Sens. Of Environ. 112, 1647-1657, https://doi:10.1016/j.rse.2007.08.006, 2008. 
Derpsch, R.: Conservation Tillage, No-Tillage and Related Technologies. In: Garcia-Torres L., Benites, J., Martinez-Viela, A., Holgado-Cabrera, A. (eds). Conservation Agri. Springer, Dordrecht, https://doi.org/10.1007/978-94-017-1143-2_23, 2003.

Fisette, T., Davidson, A., Daneshfar, B., Rollin, P., Aly, Z., Campbell, L.: Annual spaced-based crop inventory for Canada: 2009-2014. In Proc. 2014 IEEE Geosci. And Remote Sens. Symp. 13-18 July, https://doi:10.1109/IGARSS.2014.6947643, 2014.

Foody, G.M.: An assessment of citizen contributed ground reference data for land cover map accuracy assessment. In proc. ISPRS Annals of the Photogrammetry, Remote Sens. and Spatial Sci. II-3/W5, 219225, https://doi:10.5194/isprsannals-II-3-W5-219-2015.

Govaerts, B., Mezzalama, M., Unno, Y., Sayre, K.D., Luna-Guido, M., Vanherck, K., Dendooven, L., Deckers, J.: Influence of tillage, residue management, and crop rotation on soil microbial biomass and catabolic diversity. App.Soil Ecol. 37, 18-30, https://doi:10.1016/j.apsoil.2007.03.006, 2007.

Gozubuyuk, Z., Sahin, U., Ozturk, I., Celik, A., Adiguzel, M.C.: Tillage effects on certain physical and hydraulic properties of a loamy soil under a crop rotation in a semi-arid region with a cool climate. Catena, 118, 195-205, https://dx.doi.org/10.1016/j.catena.2014.01.006, 2014.

Halvorson, A., Wienhold, B.J., Black, A.L.: Tillage, Nitrogen, and Cropping System Effects on Soil Carbon Sequestration. Soil Sci. Soc. Am. J. 66: 906-912, https://doi:10.2136/sssaj2002.9060, 2002.

Hoffman, A.O., Steen-Larsen, H.C., Christianson, K., Hvidberg, C.: A low-cost autonomous rover for polar science. Geosci. Instrum. Method. Data Syst. Discuss., https://doi.org/10.5194/gi-2018-52, 2019.

Hussain, M., Chen, D., Cheng, A., Wei, H., Stanley, D.: Change detection from remotely sensed images: From pixel-based to objet-based approaches. ISPRS J. of Photogram and Remote Sens. 80, 91-106, https://dx.doi.org/10.1016/j.isprsjprs.2013.03.006

Jabro, J.D., Iversen, W.M., Stevens, W.B., Evans, R.G., Mikha, M.M., Allen, B.L.: Physical and hydraulic properties of a sandy loam soin under zero, shallow and deep tillage practices. Soil \& Tillage Res. 159, 6772, https://dx.doi.org/10.1016/j.still.2016.02.002, 2016.

Kennedy, R.E., Townsend, P.A., Gross, J.E., Cohen. W.B., Bolstad, P., Wang, Y.Q., Adams, P.: Remote sensing change detection tools for natural resource managers: Understanding concepts and tradeoffs in the design of landscape monitoring projects. Remote Sens. of Environ. 113, 1382-1396, https://doi:10.1016/j.rse.2008.07.018, 2009.

Kim, D., Paik, J.: Three-dimensional simulation method of fish-eye lens distortion for a vehicle backup rear-view camera. J. Optical Soc. Am. 32:7, 1337-1343, https://dx.doi.org/10.1364/JOSAA.32.001337.

Laamrani, A., Pardo Lara, R., Berg, A.A., Branson, D., Joosse, P.: Using a Mobile Device "App” and Proximal Remote Sensing Technologies to Assess Soil Cover Fractions on Agricultural Fields. Sensors. 18, 708: 1-16, https://doi.org/10.3390/s18030708, 2018.

Laamrani, A., Joosse, P., Feisthauer, N.: Determining the number of measurements required to estimate crop residue cover by different methods. J. of Soil and Water Cons. 72:5, 471-479, https://doi:10.2489/jswc.72.5.471, 2017. 
Mathew, R.P., Feng, Y., Githinji, L., Ankumah, R., Balkcom, S.K.: Impact of No-Tillage and Conventional Tillage Systems on Soil Microbial Communities. Appl. and Enviro. Soil Sci. 2012: 548620, 1-10, https://doi.org/10.1155/2012/548620, 2012.

Moreira, W.H., Tormena, C.A., Karlen, D.L., da Silva, A.P., Keller, T., Betioli, E. Jr.: Seasonal changes in soil physical properties under long-term no-tillage. Soil \& Tillage Res. 160, 53-64, https://dx.doi.org/10.1016/j.still.2016.02.007, 2016.

Pacheco, A., McNairn, H.: Evaluating multispectral remote sensing and spectral unmixing analysis for crop residue mapping. Remote Sens. of Environ. 114, 2219-2228, https://doi.org/10.1016/rse.2010.04.024, 2010.

Remondino, F., Gerke, M.: Oblique Aerial Imagery - A Review. In Proc. Photogramm. Wk. '15. 7-11 September, University of Stuttgart, Stuttgart Germany, 2015.

Serbin, G., Daughtry, C.S.T., Hunt, R.E., Brown, D.J., McCarty, G.W.: Effect of Soil Spectral Properties on Remote Sensing of Crop Residue Cover. Soil Sci. Soc. Am. J. 73-5, 1545-1558, https://doi:10.2136/sssaj2008.0311, 2009.

Silva-Olaya, A.M., Cerri, C.E.P., La Scala, N. Jr., Dias, C.T.S., Cerri, C.C.: Carbon dioxide emissions under different soil tillage systems in mechanically harvested sugarcane. Environ. Res. Lett. 8, 015014 8pp, https://doi:10.1088/1748-9326/8/1015014, 2013.

Spedding, T.A., Hamel, C., Mehuys, G.R., Madramootoo, C.A.: Soil microbial dynamics in maize-growing soil under different tillage and residue management systems. Soil Bio. \& Biochem. 36, 499-512, https://doi:10.1016/j.soilbio.2003.10.026, 2004.

Steiner K.: Conservation tillage - Gateway to Food Security and Sustainable Rural Development. African Conservation Tillage Network Information Series No.2. Harare:ACT.1-4, 2002.

Stockdale, C.A., Bozzini, C., Macdonald, S.E., Higgs, E.: Extracting ecological information from oblique angle terrestrial landscape photographs: Performance evaluation of the WSL Monoplotting Tool. Appl. Geog. 63, 315-325, https://doi:10.1016/j.apgeog.2015.07.015, 2015.

Thoma, D.P., Gupta, S.C., Bauer, M.E.: Evaluation of optical remote sensing models for crop residue cover assessment. J. of Soil and Water Conservation. 59:5, 224-233, 2004.

Vercammen, J.: Agri-Environmental Regulations, Policies, and Programs. Can. J. of Agri. Econ. 59, 1-18, https://doi:10.1111/j.1744-7976.2010.01210.x, 2011. 


\section{Appendix A.}

4

5

6

7

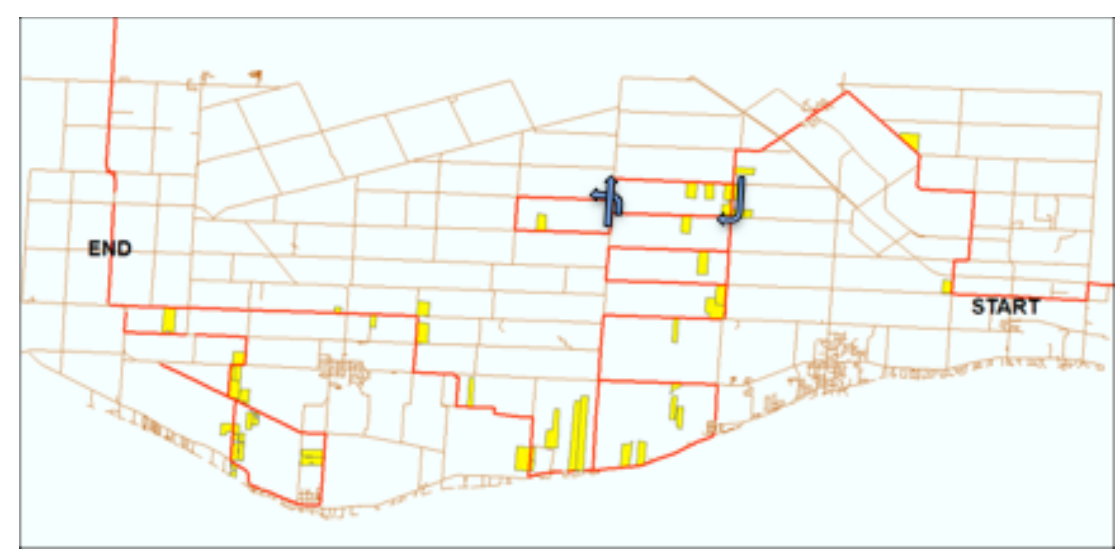

Figure A1. Essex County driving route map. AAFC fields denoted in yellow.

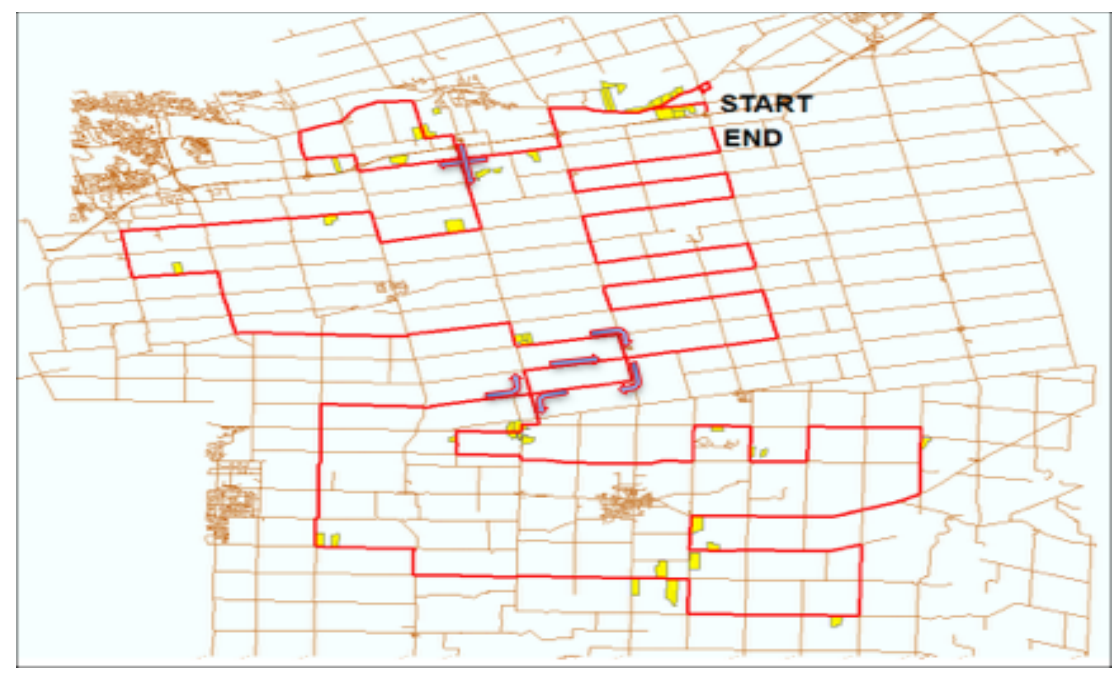

Figure A2. Elgin County driving route map. AAFC fields denoted in yellow. 